\title{
Impact of Ethical Leadership on Whistle Blowing Intention Through Medi- ating Role of Moral Attentiveness: Moderating Role of Collectivism
}

\author{
Awais Tariq* \\ Capital University of Science and Technology, Islamabad, Pakistan
}

\begin{abstract}
The focus of this research is to check the impact of leadership style on whistle blowing intention with the mediator and moderator. Using an assorted sample of 300 personnel from a variety of banks in Islamabad, the data for this field study were collected using convenient sampling technique. Ethical leadership positively influenced the process of the whistle blowing intention and provides an initiative to the employees that they can also raise their voice about any unethical conduct. Contrary to the prediction that moral attentiveness strengthens the positive role of ethical leadership verses whistle blowing relation. In addition, the cultural dimension collectivism also plays a moderating role and strengthens the relation between the moral attentiveness and whistle blowing intentions. In conclusion, this study offers significant contribution and serves to elicit comprehensive understanding of the organization to create full awareness among employees about whistle blowing intentions, providing ways by which they report the wrong doings in the organization.
\end{abstract}

\section{Introduction}

In the past decades, the researchers studied the different domains of leadership like authentic leadership, transformational leadership, servant leadership and ethical leadership. Brown et al. (2005) defined ethical leadership as the demonstration of normatively appropriate conduct through personal actions and interpersonal relationships, and the promotion of such conduct to followers through two-way communication, reinforcement, and decision-making. Treviño et al. (2003, 2000), say that the ethical leaders are generally thought as honest, trustworthy and principal decision makers, keeping in mind all the perspectives related to their organization and also by taking care of the environment in which their organization is working. There are also some conceptual frameworks of ethical leadership present that show that there are not only the organizational factors, which focus on ethical leadership, but there are also some situational factors that have an impact or determine the ethical leader. This conceptual model was given by Brown and Treviño (2006) show that the situational influences on the ethical side of the manager characterize individual and the overall outcome of the leadership style in the context of the organization and show the intensity whether employees are going to accept the ethical leadership style or not.

Another study (Kanungo and Mendonca, 2001) demonstrated that the situation has a great effect on the ethical leader and also on the decision making side of

*Corresponding author.

Email: awaistariq@gmail.com

http://www.jbrc.pk the leader, as well as on three factors that are ethical role modeling, ethical morality and ethical intensity of the issue. Ethical leader should influence employees pro social behavior. Here we have to note that ultimately ethical leaders have the legitimate role model and they have the main focus on the followers attention toward the ethical standards and the ethical activities in the organization and all it happens due to social learning (Bandura, 1986).

The relationship of ethical leadership and the employee whistle blowing activity starts from that point where the employees have their trust on their leader. Whistle blowing is an activity of reporting some wrong doings in the organization. According to Near and Micelis definition, whistle blowing is: the disclosure by organization members of illegal, immoral, or illegitimate practices under the control of their employers, to persons or organizations that may be able to effect action (Near and Miceli, 1985). This definition is comprised of three things, i.e. illegal means in term that is prohibited under the law, immoral, which means that in the perspective of the whistle blower, it is perceived as wrong and illegitimate, which means that it should be beyond the organization authority. There are also several studies present that show that the whistle blowers have such attitude to report any unethical activity in their organization and it has also been reported that the employees are more likely to report any unethical activity within a group which consists of some ethical environment (Graham, 1986). An ethical leader is re- 
sponsible for making such an ethical environment in the organization in which an employee feels safe to report any unethical activity which he or she sees in the organization.

There is literature available and also has been developed which examines this issue from different perspectives. For an extensive list of sources, see (Miceli et al., 2009). Gender difference also plays an important role, as a study by Rehg et al. (2008) reported that females are being more retaliated toward this issue; i.e. being female was correlated with perceived retaliation (pp.221-240) against whistle blowing; Similarly, another study reports that there are some incentives for those employees and these incentives are being given on the basis of gender (Feldman and Lobel, 2009).

Social cognitive theory given by Bandaura is most effectively related to our study. Specifically social cognitive theory covers all the variables in our study. Social cognitive theory first defined by a psychologist Albert Bandura in 1997 which he defines as Social cognitive theory (SCT), used in psychology, education, and communication, holds that portions of an individual's knowledge acquisition be directly related to observing others within the context of social interactions, experiences, and outside media influences. Based on social cognitive theorys social learning (Bandura, 1977, 1986), Brown et al. (2005) argued that ethical leaders influence followers primarily through modeling processes. The modeling refers to the learning by an individual through their environment by using their mental schemas to evaluate or to note what is happening in the environment and the environment also plays an important role that how a person learns from the environment either in a positive or negative way.

Banduara's social learning theory stresses the importance of things the human beings learn from their environment through the imitation of different things and through the modeling process that we have discussed above. The theory also integrates a continuous process of interaction between the human behaviors, other personal factors, including all those cognitions that are related with the cognition and with the environment, which are being referred as the reciprocal process causation model.

When we are talking about the social learning process, it means what an individual learns from his environment and his workplace. If an organization is ethical and all the employees who are working in that organization are behaving ethically, then automatically those ethical values are being transferred to the employees and above all, a complete ethical atmosphere is being developed and this happens due to the ethical leader. The other leadership styles are also considered for development of ethical values in the organization, as servant leadership has focused on the power distance and the human orientation that can also be synergied with the process or with the help of ethical leadership.

Another main and important thing is that there must be a strong determination of the leader to be ethical, who plays an important role in developing the ethical role models in the organization. This can only happen in the organization, when the leader himself is ethical and has strong determination to be ethical. But if there is no determination of the leader to be ethical then he or she cannot inculcate ethical conscientious among employees.

\section{Literature Review}

\subsection{Ethical leadership and whistle blowing}

There are different researches being conducted in a different formats by taking ethical leadership and also have been checked with the different variables, but when there is hype created in whole world about missrepresenting or some wrongdoing in the organization that raises the question on the ethical leadership. When the media reported the cases about the WorldCom and Enron, the questions were asked to the CEOs of different organization association between ethical leadership and financial misrepresenting of the data (Perel, 2003). Different studies on financial scam in the business ethics literature have focused on the character and honesty of different Chief Executive of several organizations (Bragues, 2008; Morrison, 2001)and tried to answer the question of what ethical leaders should do from a entirely philosophical view based on ethical principles, which are based on ethics taken from Greek philosophers such as Plato and Aristotle (Knights and OLeary, 2006; MacIntyre, 1979).

Different studies in which they have taken a scientific approach, which deal with the ethics within the organization, the contextual factors and also the situational factors, which help ethical leader to build an ethical workplace. Such situational factors are ethical context in which the employees or the followers have trust on their leader and show the follower satisfaction while working with his or her leader (Brown and Treviño, 2006; Brown et al., 2005). Different studies have been carried out on the significance of culture values and norms in determining the behaviors of ethical leaders. The GLOBE study, which focused on comparison between perceptions of leadership among different countries established that character or integrity was sanctioned much less among societies of Middle Eastern countries as compared to the societies of Nordic (Resick et al., 2006; Waldman et al., 2006).

Based on the above literature, following hypothesis has been developed.

H1. There is a positive relationship between ethical; leadership and whistle blowing 


\subsection{Moral Attentiveness mediates the re- lationship between Ethical Leadership and Whistle Blowing}

There are different variables being discussed by the researcher when they are discussing the ethical leadership and whistle blowing so the current study takes a new construct, i.e. moral attentiveness as a mediating variable. This construct is considered very important in part of the ethical leadership, which is being discussed by Waldman et al. (2006). New thing is also being proposed by the followers that the leaders who have high moral attentiveness is considered ethical by their followers. It is of utmost importance that the followers should consider their leader ethical so the ethical values are automatically being transferred in the employees, consequently leading to whistle blowing by the employees, if they have strong ethical values. Researcher have shown that moral attentiveness is considered a trait like character in the followers and it all happens due to ethical leadership and if that trait is being transferred through the ethical leadership then the employees are being more attentive, all the while noticing or seeing any wrongdoing in the organization, they will definitely report that thing. Moral identity and moral attentiveness are being both inculcated by the ethical leader but the moral attentiveness is main thing which is being developed by ethical leader (Mayer et al., 2012). One of the critical factors which affects an individual's sensitivity towards ethical issues is a moral interest, a relatively new construct in the ethical literature, known as "the extent to which envisages chronic individual is ethics and moral elements of his proposed" based on social cognitive theory of knowledge (Bandura, 1986). Reynolds (2008) proposed that some individuals are more interested in cognitive ethical issues than others, and that the moral interest of individuals has a significant impact on experiences. Thus, leaders who are highly morally attentive should pay more attention to the moral aspects of the information the receive.

H2. Moral attentiveness mediates the relationship between ethical leadership and whistle blowing.

\subsection{Collectivism as a moderator between Moral Attentiveness and whistle blow- ing}

There are different cultural dimensions being discussed; such as individualism and collectivism, we have taken collectivism in our research because this research is being conducted in Pakistan, where where collectivisim is dominant in our culture as suggested by Hofstede (1986). The cultural dimension also shows how much an individual stresses his or her own goals or on the other hand the goal of his or her group. Results suggest that in Pakistan a number of factors, such as culture and organizational retaliation, affect the whistle-blowing process. It also highlights that some unique culturally induced factors contribute toward the employees perception and practice of whistle blowing in their organizations. Results are explained in light of Hofstedes cultural indices, which indicate that whistle blowing is culture bound.

There are different ways through which the reporting of whistle blowing or any wrong doing is to be done. Basically, whistle blowing is commonly defined as the disclosure by organization members (former or current) of illegal, immoral, or illegitimate practices under the control of their employers, to persons or organizations that may be able to effect action (Near and Miceli, 1985). Employee utilization channels to report the wrong doings or any misconduct are not sufficient and therefore they are less in amount so in different studies it is being found that employees that are aware of wrongdoing and any type of corruption in the organization, they remain quiet and dont tell anyone about that wrong doing (Near and Miceli, 1985). An employees decision to report individual or organizational misconduct is a complex phenomenon that is based upon organizational, situational, and personal factors (Near and Miceli, 1995).

H3. Collectivism moderates the relationship between moral attentiveness and whistle blowing

\section{Theoretical framework}

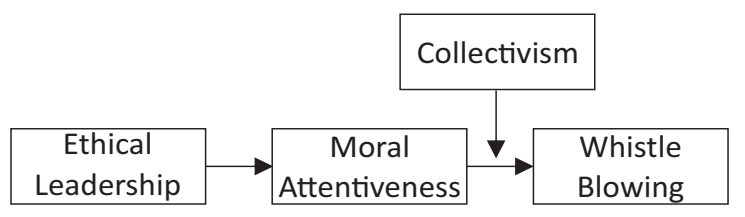

Figure 1: Theoretical Framework

\section{Research Methodology}

\subsection{Population and Sample}

Since the present study seeks to focus on the public sector of Pakistan, the population of the study is the employees of schools and college. The sample mainly consists of administration level of different schools and colleges. Data were collected through a self-administered paper-and-pencil survey. Almost 300 questionnaires were distributed. The convenience sampling technique were used due to time limitations. 


\subsection{Instrumentation}

All the items in the questionnaire were responded to using a 5-points Likert-scale where 1 (strongly disagree) to 5 (strongly agree), unless otherwise stated. Questionnaires also consist of four demographic variables which include information regarding the respondent Gender, Age, Qualification and Experience.

\subsubsection{Ethical leadership}

The 10 item scale developed by Yukl et al. (2013) was used to measure the perception of employees about their leaders ethical behavior. The items show strong concern for ethical and moral values which communicate clear ethical standards for members sets an example of ethical behavior in his/her decisions and actions. Is honest and can be trusted to tell the truth, Is a fair and unbiased when assigning task to members..

\subsubsection{Moral attentiveness}

The 7 item scale developed by Reynolds (2008) was adoped to measure moral attentiveness. The item scale is. I regularly think about the ethical implications of my decisions, I think about the morality of my actions almost every day, I often find myself pondering about ethical issues, I often reflect on the moral aspects of my decisions, I like to think about ethics, In a typical day, I face several ethical dilemmas, I often have to choose between doing whats right and doing something thats wrong..

\subsubsection{Collectivism}

To measure collectivism, 5 item scale developed by Williams et al. (1988) was used. The item scales are Group welfare is more important than individual rewards, Group success is more important than individual success, Being accepted by the members of your workgroup is very important, Employees should only pursue their goals after considering the welfare of the group, and Managers should encourage group loyalty even if individual goals suffer.

\subsubsection{Whistle Blowing}

The 2-item scale developed by Bhal and Dadhich (2011) was adopted to guage the responses of whistle blowing. The scale items are as follows, I feel that I can discuss ethical issues and problems with my supervisor without fear of having the comments held against me, I would be comfortable delivering bad news of an unethical wrongdoing to the supervisor..

\subsection{Sample Characteristics}

Out of the 180 total respondents, majority were young. The respondent between age 18 to 25 years were 113, while the respondents of 26 to 33 year age were 56, as the age between 18 and 33 considered young, they contributed $82.2 \%$ of the total responses of the present study. The middle aged respondents from age 34 to 41 years were 8 and the respondents of age 42 to 49 years were 3 . In the total sample of 180 the population, 103 were male and 77 were female, having percentage of $57.2 \%$ and $42.8 \%$ respectively. As expected, male employees are working in majority then female colleagues, thus showing consistency with perceptions about that Pakistani culture male dominant society.

\section{Results}

\subsection{Correlation analysis}

Table 1 displays the correlation between the variables of the current study. Ethical Leadership is significantly positively correlated to whistle blowing intention at $.663^{* *}$. The maximum value of correlation found was $.705^{* *}$ which was between ethical leadership and moral attentiveness. Whereas, ethical leadership correlates with the collectivism and the correlation value between the ethical leadership and collectivism is .591**. Further in this table other variables also shows the correlation as collectivism correlates between moral attentiveness and whistle blowing intention with a values of $.609^{* *}$ and $.687^{* *}$ respectively. In the last moral attentiveness correlates between whistle blowing intention with a value of $.609^{* *}$.

\subsection{Regression Analysis}

Regression analysis between ethical leadership and moral attentiveness resulted in the $R^{2}$ value of 0.50 , representing that ethical leadership brings $50 \%$ change in the moral attentiveness of followers. Moral attentiveness when regressed with ethical leadership had a statistically significant results. As proposed by the research model, ethical leadership predicts approximately 50 percent variation in moral attentiveness in a positive direction, which is consistent with the study hypothesis. The $R^{2}$ value is 0.50 at $\mathrm{p}<.05$ (table 2 ). Thus concluded that 1 unit change in ethical leadership results in nearly 0.5 percent change in moral attentiveness. Therefore, H2, which indicated that ethical leadership positively affects followers moral attentiveness, substantiated statistically.

Regression analysis between moral attentiveness and whistle blowing intention resulted in the $R^{2}$ value of 0.48 , representing that moral attentiveness brings $48 \%$ change in the whistle blowing intention of followers. Whistle blowing intention when regressed with moral attentiveness also showed significant results. As proposed by the research model, moral attentiveness predicts approximately 48 percent variation in whistle blowing intention in a positive direction, which is con- 
Table 1: Means, Standard Deviations, Correlations, Reliabilities

\begin{tabular}{llcccccc}
\hline & Variables & Mean & S.D & $\mathbf{1}$ & $\mathbf{2}$ & $\mathbf{3}$ & $\mathbf{4}$ \\
\hline $\mathbf{1}$ & Ethical Leadership & 4.7 & 0.9 & $\mathbf{1}(.706)$ & & & \\
$\mathbf{2}$ & Moral Attentiveness & 5 & 0.9 & $.705^{* *}$ & $\mathbf{1 ( . 7 4 3 )}$ & & \\
$\mathbf{3}$ & Whistle Blowing Intentions & 4.83 & 1 & $.663^{* *}$ & $.609^{* *}$ & $\mathbf{1 ( . 6 5 9 )}$ & \\
$\mathbf{4}$ & Collectivism & 4.8 & 1 & $.591^{* *}$ & $.687^{* *}$ & $.629^{* *}$ & $\mathbf{1 ( . 6 4 2 )}$ \\
\hline
\end{tabular}

*. Correlation is significant at the 0.05 level (2-tailed)

**. Correlation is significant at the 0.01 level (2-tailed)

Table 2: Regression Analysis

\begin{tabular}{lccc}
\hline Relationships & $R^{2}$ & F & Sig \\
\hline Ethical Leadership Moral Attentiveness & 0.5 & 175.49 & 0.000 \\
Ethical Leadership and Moral Attentiveness Whistle Blowing Intentions & 0.48 & 81.65 & 0.000 \\
Ethical Leadership Whistle Blowing Intentions (total effect model) & 0.44 & 139.79 & 0.000 \\
\hline
\end{tabular}

sistent with the study hypothesis. The beta value is 0.48 at $\mathrm{p}<.05$. Therefore concluded that 1 unit change in moral attentiveness results in nearly 0.4 percent change in whistle blowing intention. Therefore, $\mathrm{H} 2$, which indicated that ethical leadership positively, affects followers moral attentiveness, substantiated statistically.

Regression analysis between ethical leadership and whistle blowing intention resulted in the $\mathrm{R} 2$ value of 0.44 , representing that ethical leadership brings $44 \%$ change in the whistle blowing intention of followers. Whistle blowing intention when regressed with ethical leadership had a statistically significant model. As proposed by the research model, ethical leadership predicts approximately 44 percent variation in whistle blowing intention in a positive direction, which is consistent with the study hypothesis. The $R^{2}$ value is 0.44 at $\mathrm{p}<.05$ (table 2). Thus, it can be deduced that 1 unit change in ethical leadership results in nearly 0.4 percent change in whistle blowing intention. Therefore, H1, which indicated that ethical leadership positively affects followers whistle blowing intention, substantiated statistically.

A mediation analysis was run through SPSS using PROCESS macro by Preacher and Hayes. Model 4 according Hayes templates works as a mediation model. In the mediation model (table 3 ), the effect of ethical leadership can be partitioned into two parts: 1) the direct effect of EL on WB, and 2) the indirect effect of Ethical leadership on Whistle blowing intention via Moral attentiveness. Combined, the direct and indirect effect of EL on WB or the total effect is 0.72 with positive sign implying the positive relationship. Hence, hypothesis 1 is accepted which stated a positive association between ethical leadership and whistle blowing.

The direct effect of EL on WB when the mediator is included in the model turns out to be 0.50 with positive sign implying a positive relationship between EL and WB. The indirect or mediation effect which is a measure of how much of the effect of EL on WB is being mediated comes out to be 0.22 and is significant with no zero value lying between the upper and lower boot values of confidence interval. Therefore, we accept $\mathrm{H} 2$, i.e. MA mediates the relationship between EL and WB.

Using PROCESS macro, the results of moderation analysis according to table 4 demonstrate that the change in $R^{2}$ due to collectivism as a moderator comes out to be 0.029 , with a significant $p$ value. Therefore, we infer that collectivism moderates between MA and WBI, i.e. H3 is accepted subsequently. A moderation plot is also given for more clarity.

\section{Implications and Recommenda- tions}

\subsection{Theoretical implications}

There are many theoretical implications of the current study which are discussed below:

Firstly, the present study introduced collectivism as 
Table 3: Mediated Regression

\begin{tabular}{lcccccc}
\hline & Effect & SE & T & P & BootLLCI & BootULCI \\
\hline Total effect & 0.72 & 0.06 & 11.82 & 0.00 & 0.60 & 0.84 \\
Direct effect & 0.5 & 0.08 & 6.08 & 0.00 & 0.34 & 0.67 \\
Indirect effect & 0.22 & 0.06 & - & - & 0.1 & 0.35 \\
\hline
\end{tabular}

Table 4: Moderation Analysis

\begin{tabular}{cccc}
\hline & $\Delta R^{2}$ & F & P \\
\hline Moral Attentiveness x Whistle Blowing Intentions & 0.029 & 9.99 & 0.0018 \\
\hline
\end{tabular}

$n=180$

a moderator between moral attentiveness and whistle blowing intention. Collectivism was tested to see its results on whistle blowing intention. Previously, collectivism was tested in major studies to check the impact that either culture has some impact on the overall research or not. Major studies has revealed that the cultural differences plays a vital role in different studies and it also shows the importance that difference in the cultural values also shows the difference in the perception of the employees that how they perceive the word of whistle blowing intention. The word intentions means that it varies in different people that how much cost they have to pay for reporting any wrongdoing in the organization and this cost is measured when we have to do cross cultural comparison.

Secondly, the present research also studied the moral attentiveness as a mediator in this study. Moral attentiveness means how much the employee is attentive in the working environment. Employees who are morally attentive are sometimes loyal to the organization because they always try to work for the benefit for the organization. In Pakistan, there is a great need for such people who are working in the organization, to be morally attentive, such that if they would see any wrongdoing in the organization they will definitely report it.

Thirdly, the study also helps to understand the effects of the ethical leadership and how it enhances performance of employees in terms of moral attentiveness, especially those employees who are working in Pakistani organizations. Very scarce and few researches are available on whistle blowing intention and even fewer are available in Pakistani context. Most of the studies conducted on ethical leadership in relationship with whistle blowing intention are in western societies, which are individualistic culture and low power distance societies.

Moreover,, the study provides support for the So- cial Cognitive Theory (SCT), which proposes that people build the relationships and these relationships are built when the employees are working in the organization, they learn through observing others and from the social media or print media; consequently, they make decisions that are favorable in the perspective of the organization.

Future researchers are advised to investigate the same study using longitudinal study. The researchers should also consider investigating the current relationships for a specific type of different leadership style with whistle blowing intentions. Furthermore, other dimensions should also be explored, such as masculinity, femininity and power distance. Power distance must be checked, as Pakistan is high on power distance, it must be interesting to explore, whether employees do move towards whistle blowing in presence of high power distance.

Further, the researchers should find that what are the actual reasons for starting the whistle blowing process and what are the elements that initiate the process of whistle blowing. The current study just checked the impact of ethical leadership, which would start the process of whistle blowing intentions in the employees.

\subsection{Practical implications}

The present study has certain practical implications, which might provide some help for the organizations in Pakistan. It can be noticed that whistle blowing or whistle blowing intention is a great concern for the organization because as we see in the organizations that are working in Pakistan, large number of cases are present that show that the people have no fear of doing any wrongdoing. Peoples know that there are no proper authority that can check there wrongdoing so there is great need of an ethical leader and a proper channel of reporting the wrongdoing. 
The study will also provide guidance for Pakistani organizations to develop their working environment in which the employees have no fear of reporting any wrongdoing in the organization. It is the duty of the organization to provide such working environment that will be helpful for the employees to report the wrongdoing.

\subsection{Limitations}

The current study tried to eliminate all the problems, but still there are some limitations that must be avoided in the future.

Firstly, that sampling and data collection were done through cross sectional method due to time and resource constraints. In a cross sectional study data are collected from the respondents at one specific point of time. Thus, the sample size was small and might not represent all the population of Pakistan, because the sample was not comprehensive and results might change if sample size might increase.

Moreover, the study focused on different sectors for data collection, but it might also affect the results of this study. Because working conditions of the banking sector organization might offer more support and when we analyses the corporate scandals that occurs in different organizations, it may provide more comprehensive support and facilitation to employees as compared to other sectors that might not support and facilitate their disabled employees much.

\section{References}

Bandura, A. (1977). Self-efficacy: toward a unifying theory of behavioral change. Psychological review, 84(2):191.

Bandura, A. (1986). The explanatory and predictive scope of self-efficacy theory. Journal of social and clinical psychology, 4(3):359-373.

Bhal, K. T. and Dadhich, A. (2011). Impact of ethical leadership and leader-member exchange on whistle blowing: The moderating impact of the moral intensity of the issue. Journal of Business Ethics, 103(3):485-496.

Bragues, G. (2008). The ancients against the moderns: Focusing on the character of corporate leaders. Journal of Business Ethics, 78(3):373-387.

Brown, M. E. and Treviño, L. K. (2006). Ethical leadership: A review and future directions. The leadership quarterly, 17(6):595-616.

Brown, M. E., Treviño, L. K., and Harrison, D. A. (2005). Ethical leadership: A social learning perspective for construct development and testing. Organizational behavior and human decision processes, 97(2):117-134.
Feldman, Y. and Lobel, O. (2009). The incentives matrix: The comparative effectiveness of rewards, liabilities, duties, and protections for reporting illegality. Tex. L. Rev., $88: 1151$.

Graham, J. W. (1986). Principled organizational dissent: A theoretical essay. Research in organizational behavior.

Hofstede, G. (1986). The usefulness of the organizational cultureconcept. Journal of Management Studies, 23(3):253-257.

Kanungo, R. N. and Mendonca, M. (2001). Ethical leadership and governance in organizations: A preamble. Canadian Journal of Administrative Sciences, 18(4):241.

Knights, D. and OLeary, M. (2006). Leadership, ethics and responsibility to the other. Journal of Business Ethics, 67(2):125-137.

MacIntyre, A. C. (1979). Corporate modernity and moral judgment: Are they mutually exclusive? University of NotreDame Press.

Mayer, D. M., Aquino, K., Greenbaum, R. L., and Kuenzi, M. (2012). Who displays ethical leadership, and why does it matter? an examination of antecedents and consequences of ethical leadership. Academy of Management Journal, 55(1):151-171.

Miceli, M. P., Near, J. P., and Dworkin, T. M. (2009). A word to the wise: How managers and policy-makers can encourage employees to report wrongdoing. Journal of Business Ethics, 86(3):379-396.

Morrison, A. (2001). Integrity and global leadership. Journal of Business Ethics, 31(1):65-76.

Near, J. P. and Miceli, M. P. (1985). Organizational dissidence: The case of whistle-blowing. Journal of Business Ethics, $4(1): 1-16$.

Near, J. P. and Miceli, M. P. (1995). Effective-whistle blowing. Academy of management review, 20(3):679-708.

Perel, M. (2003). An ethical perspective on ceo compensation. Journal of Business Ethics, 48(4):381-391.

Rehg, M. T., Miceli, M. P., Near, J. P., and Van Scotter, J. R. (2008). Antecedents and outcomes of retaliation against whistleblowers: Gender differences and power relationships. Organization Science, 19(2):221-240.

Resick, C. J., Hanges, P. J., Dickson, M. W., and Mitchelson, J. K. (2006). A cross-cultural examination of the endorsement of ethical leadership. Journal of Business Ethics, 63(4):345-359.

Reynolds, S. J. (2008). Moral attentiveness: Who pays attention to the moral aspects of life? Journal of Applied Psychology, 93(5):1027.

Treviño, L. K., Brown, M., and Hartman, L. P. (2003). A qualitative investigation of perceived executive ethical leadership: Perceptions from inside and outside the executive suite. Human relations, 56(1):5-37. 
Treviño, L. K., Hartman, L. P., and Brown, M. (2000). Moral person and moral manager: How executives develop a reputation for ethical leadership. California management review, 42(4):128-142.

Waldman, D. A., De Luque, M. S., Washburn, N., House, R. J., Adetoun, B., Barrasa, A., Bobina, M., Bodur, M., Chen, Y.-J., Debbarma, S., et al. (2006). Cultural and leadership predictors of corporate social responsibility values of top management: A globe study of 15 countries. Journal of International Business Studies, 37(6):823-837.
Williams, M. L., Podsakoff, P. M., Todor, W. D., Huber, V. L., Howell, J. P., and Dorfman, P. W. (1988). A preliminary analysis of the construct validity of kerr \& jermier's substitutes for leadershipscales. Journal of Occupational and Organizational Psychology, 61(4):307-333.

Yukl, G., Mahsud, R., Hassan, S., and Prussia, G. E. (2013). An improved measure of ethical leadership. Journal of leadership E organizational studies, 20(1):38-48. 